\title{
Pregnancy outcome after insemination of frozen-thawed bovine semen packaged in two straw sizes: A meta-analysis ${ }^{1}$
}

\author{
J. S. Stevenson, ${ }^{2}$ J. J. Higgins, $†$ and Y. Jung† \\ *Department of Animal Sciences and Industry, and \\ †Department of Statistics, Kansas State University, Manhattan 66506
}

\section{ABSTRACT}

The $0.25-\mathrm{mL}$ French straw has been thoroughly studied and compared with the 0.5 -mL French straw for about $40 \mathrm{yr}$. The $0.25-\mathrm{mL}$ straw has some distinct advantages over the $0.5-\mathrm{mL}$ straw in terms of storage efficiency and extender usage. The $0.25-\mathrm{mL}$ straw is more sensitive to temperature change, which may be an advantage in some freezing systems with a slow freezing rate, but provides no advantage when the freezing rate is accelerated to optimize freezing in $0.5-\mathrm{mL}$ straws. Disadvantages of the $0.25-\mathrm{mL}$ straw include increased sensitivity to post-thaw temperature change, slightly more difficult handling, and inferior readability. Fertility of cattle inseminated with extended semen packaged in 0.25 -mL straws assessed in 13 studies $(>770,000$ inseminations) had a weighted advantage of $0.9 \%(0.7 \%$ unweighted advantage) compared with semen packaged in 0.5 -mL straws. In 2 studies in which palpated conception rates were obtained, the weighted advantage of the $0.25-\mathrm{mL}$ versus the $0.5-\mathrm{mL}$ straw was $0.2 \%$ (0.4\% unweighted advantage). Paired $t$-tests did not detect a significant difference in pregnancy outcome between straw sizes. Logistic regression of all 15 studies ( $>780,000$ inseminations) detected large variation among studies and tended to detect a small advantage for the $0.25-\mathrm{mL}$ straw. Meta-analyses applied to fixedor random-effect models of all 15 studies indicated the average odds of having a greater pregnancy outcome with the $0.25-\mathrm{mL}$ straw were either 3 or $4 \%$ greater. Based on these odds ratios, the expected proportion of difference in pregnancy outcome translated into a difference of $0.74 \%$. These small differences in pregnancy outcomes do not provide compelling evidence that a transition from 0.50 - to $0.25-\mathrm{mL}$ straws in the United States is warranted, especially given the added negative aspects of semen handling and the greater potential for

Received April 16, 2009

Accepted May 27, 2009.

${ }^{1}$ Contribution number 09-268-J from the Kansas Agricultural Experiment Station, Manhattan 66506

${ }^{2}$ Corresponding author: jss@k-state.edu technician $\times$ straw type interactions among herdsman inseminators.

Key words: artificial insemination straw package, pregnancy outcome, meta-analysis

\section{INTRODUCTION}

The history of preserving bovine semen in straws was reviewed by Pickett and Berndtson (1974). Some clear benefits existed for freezing extended semen in straws compared with glass ampules: 1) comparable conception rates, 2) comparable or better sperm survival in storage, 3) comparable doses of sperm to achieve optimal fertility, and 4) reduced storage space. In the United States, glass ampules were replaced by the French straw during the early 1970s.

Plastic straws for packaging liquid semen were first introduced in Denmark in 1940. Later, techniques for freezing semen in straws were developed and refined by Cassou and Jondet (Pickett and Berndtson, 1974). During the 1960s, Cassou (1972) introduced a mediumsized, polyvinyl chloride straw with a diameter of 2.8 $\mathrm{mm}$ and volume of $0.5 \mathrm{~mL}$, which replaced a larger straw with a diameter of $4.2 \mathrm{~mm}$ and volume of 1.2 $\mathrm{mL}$. In 1968, Cassou introduced the $0.25-\mathrm{mL}$ straw that remains in use today.

Comparing the relative merits of $0.25-$ and $0.5-\mathrm{mL}$ straws reveals at least 3 obvious differences: 1 ) the $0.25-\mathrm{mL}$ straw required less extender to fill and less space to store, potentially reducing production, storage, and shipping costs (Senger et al., 1983; Kroetsch, 1992; Johnson et al., 1995); 2) the larger 0.5-mL straw was easier to handle, easier to read, and may (DeJarnette, 2003) or may not suffer less breakage during storage (Kroetsch, 1992); and 3) the 0.25 -mL straws responded to temperature changes faster than the $0.5-\mathrm{mL}$ straws (Berndtson et al., 1976). Whether this latter characteristic is positive or negative has been the subject of debate for more than $40 \mathrm{yr}$, and the research regarding the fertility of cattle inseminated with frozen-thawed semen packaged in 0.25 - or $0.5-\mathrm{mL}$ straws over those years has often had conflicting results, conclusions, and interpretations. 
In the 1970s, commercial AI organizations in Europe and Canada adopted the smaller diameter $0.25-\mathrm{mL}$ straw, whereas AI organizations in the United States and most countries in Latin America opted to use the $0.5-\mathrm{mL}$ straw. This technology divergence among countries was largely based on the perceived degree of variance in inseminator skills, training, and proficiency within each respective country. In Europe and Canada, about $90 \%$ of all inseminations in the early 1970s were performed by highly skilled professional AI technicians employed by the AI centers (Kupferschmied, 1972). Post-thaw semen handling issues were of lesser concern than in the United States, wherein the trend had been for greater use by herdsman inseminators, who by definition possess more varied levels of expertise (Berndtson et al., 1976).

The objective of this review and meta-analysis of available data was to determine whether any advantage in fertility existed for using the 0.25 - vs. $0.5-\mathrm{mL}$ French straw for cryopreserved bovine semen.

\section{MATERIALS AND METHODS}

We examined 15 studies (1967 to 2007) that reported nonreturn rates $(\mathrm{n}=12)$, blood concentrations of pregnancy-specific protein $\mathrm{B}(\mathrm{n}=1)$, or actual palpated conception rates $(\mathrm{n}=2)$ of dairy cattle inseminated with frozen-thawed semen packaged in either 0.25 - or 0.5-mL plastic straws (Table 1). In total, these studies represent more than 780,000 inseminations.

\section{Statistical Analyses}

Three different statistical methods were applied to the 15 studies to detect differences in pregnancy outcome according to straw package size. First, means were compared by a paired $t$-test that gave equal weight to all proportions reported in the 15 studies. Second, results were analyzed by weighted logistic regression. Third, data were analyzed by meta-analysis.

Analyses were made for different subsets of the 15 studies when using the paired $t$-test and logistic regression. Twelve studies used nonreturn rates (most were 60 to $90 \mathrm{~d}$ after AI; Table 1) to assess pregnancy outcomes, whereas a 13th study used concentrations of pregnancyspecific protein B in blood collected between 30 and 45 $\mathrm{d}$ after AI. Because relative pregnancy outcomes were in the same range (62.0 to $76.7 \%$ ), these 13 studies were analyzed together. A second subset included 2 studies in which palpated conception rates were determined between 35 and $42 \mathrm{~d}$ (Michael et al., 2003) or $60 \mathrm{~d}$ after AI (Schenk and Everett, 2007). Mean conception rates were similar and ranged from 24.4 to $31.3 \%$. A third analysis included results from all 15 studies.
Paired $\boldsymbol{t}$-Test. Proportions (p) for pregnancy outcome for each straw size were converted to logits:

$$
\log _{\mathrm{e}}\left(\frac{\mathrm{p}}{1-\mathrm{p}}\right) .
$$

Logit values were analyzed with a standard paired $t$-test (Minitab Inc., State College, PA). Means, standard deviations, and standard errors for treatments are reported. In addition, means, standard deviations, standard error of the difference between treatments, the $95 \%$ confidence intervals, $t$ statistics, and $P$-values are reported here and throughout.

Logistic Regression. Weighted logistic regression analyses were conducted on the study proportions for each straw size. Two models were constructed. The first model included the main effects of straw size and study and their interaction. The second model ignored the interaction term. Models were applied to weighted data including options (distribution $=$ binomial and link $=$ logit) in procedure GENMOD (SAS Institute Inc., Cary, NC). Type III sum of squares were used. Odds ratios were calculated from the mean difference (MD) between treatments $\left(\mathrm{e}^{\mathrm{MD}}\right)$, and the Wald statistic was used to calculate $95 \%$ confidence limits. Actual proportion (p) values were calculated from the mean logit:

$$
\mathrm{p}=\left(\frac{\mathrm{e}^{\text {mean }}}{1+\mathrm{e}^{\text {mean }}}\right) .
$$

Meta-Analyses. The software package R (http:// www.r-project.org) was used to conduct several metaanalyses based on principles described by Wolf (1986). The functions meta.MH and meta.DSL in the rmeta package were used, and 2 models were executed. The Mantel-Haenszel method was applied to the data in a fixed-effects meta-analysis, whereas the DerSimonianLaird method was used for random-effects meta-analysis. Odds ratios of individual studies were calculated in addition to their $95 \%$ confidence limits. Each analysis that included fixed or random effects determined an overall odds ratio and a test for heterogeneity.

\section{RESULTS}

Some of the 15 studies examined included various factors that were confounded with straw size. For example, variations in nonreturn rates (most were 60 to $90 \mathrm{~d}$ after AI), sperm dose per straw package, number of bulls sampled, and study duration were identified among studies (Table 1). The 2 largest and oldest studies reported differences between the 2 straw sizes, but 
Table 1. Comparison of fertility of cattle inseminated with semen packaged in 0.25 - or 0.5 -mL straws

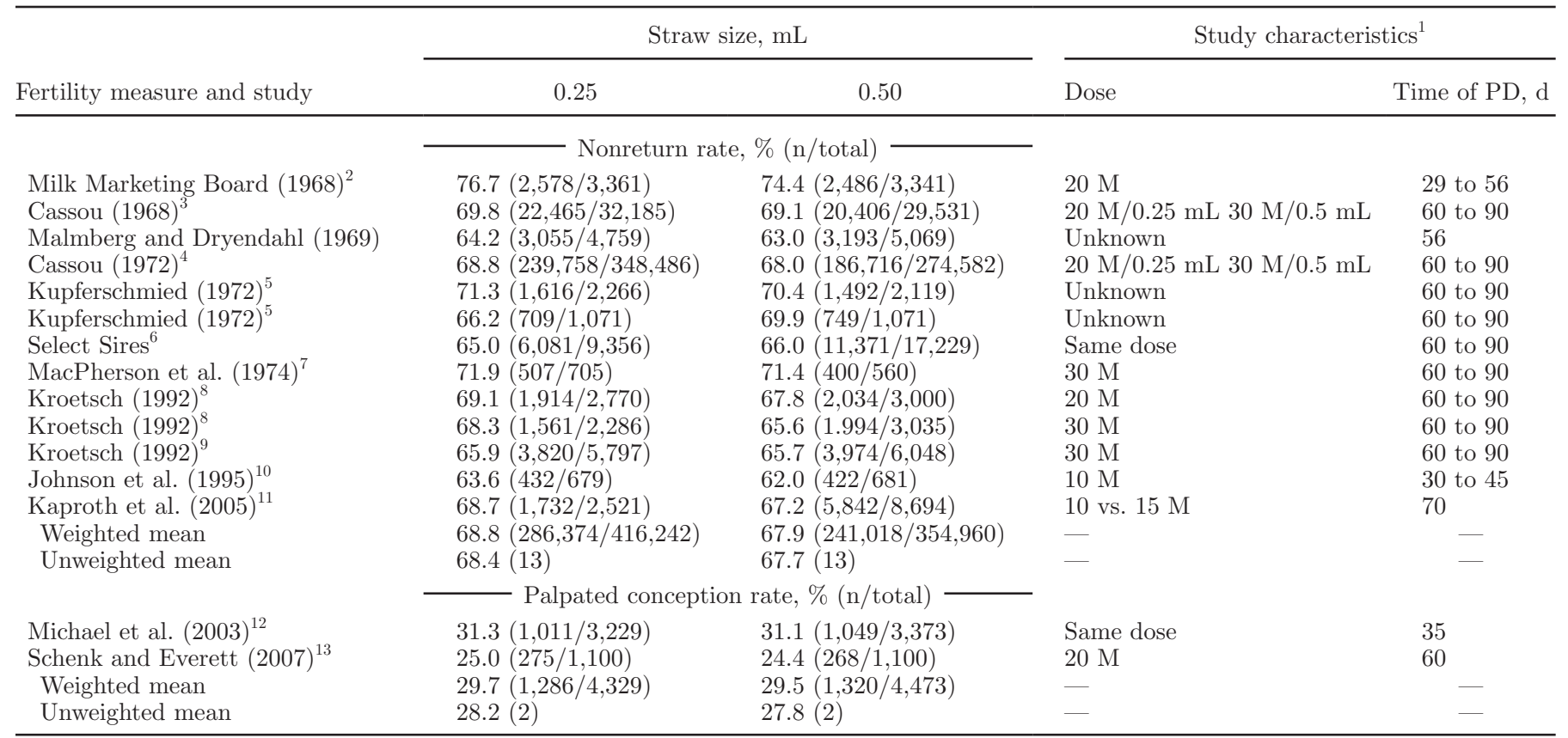

${ }^{1}$ Studies were conducted in lactating dairy cattle except where noted. Dose of sperm per straw, $\mathrm{M}=$ million; and time (days since last reported $\mathrm{AI})$ of pregnancy diagnosis (PD).

${ }^{2}$ Caprogen extender; 48 technicians; 3 Friesian bulls.

${ }^{3} 58$ bulls; 75 AI technicians; 5-mo study; first services.

${ }^{4} 100$ bulls; 82 AI technicians; 37-mo study; first services.

"Good" vs. "poor" AI technicians, respectively.

${ }^{6} 23$ bulls; 11-mo study (J. Mel DeJarnette, Select Sires, Plain City, OH; personal communication).

${ }^{7} 12$ bulls (split collection); pocket thaw; experienced technicians; first services.

${ }^{8} 5$ bulls; whole milk extender; first services.

${ }^{9} 25$ bulls; Tris-egg extender; 280 AI technicians; first services.

${ }^{10}$ Pregnancy-specific protein B was used to detect pregnancy in blood samples collected once between 30 and $45 \mathrm{~d}$ after AI; 5 bulls (split collection); 12-mo duration; dairy heifers.

${ }^{11}$ Pocket vs. warm-water thaw; milk extender; 12 bulls; 16-mo duration; dairy heifers.

${ }^{12} 8$ bulls (split collections); 7 technicians; 9-mo duration.

${ }^{13}$ Sexed-biased semen (split collections); 3 bulls; at least 7 technicians.

straw size was confounded with numbers of sperm packaged (Cassou, 1968, 1972; Table 1). In another study (Kaproth et al., 2005), 55\% of the total observations analyzed for pregnancy outcome represented semen packaged only in 0.5 -mL straws. Therefore, only $45 \%$ of the data analyzed represented a comparison of the same semen in both straw packages.

In most studies, semen collections were split and stored in both straw packages. Some studies were conducted in heifers, others in lactating cows. Nevertheless, nearly all studies analyzed were published in the scientific literature (a few were only abstracts) except for one extensive in-house study conducted in 1972 by Select Sires (J. Mel DeJarnette, Select Sires, Plain City, $\mathrm{OH}$; personal communication), which represented split collections of 23 bulls packaged in both straw types with contemporary inseminations of frozen-thawed semen carried out during an 11-mo study.
Other industry-generated data exist but were not analyzed because they did not represent contemporary comparisons in which semen from the same bulls packaged in 0.25 - or $0.5-\mathrm{mL}$ straws was used to inseminate cows during the same period.

Fertility of cattle inseminated with extended semen packaged in $0.25-\mathrm{mL}$ straws assessed in 13 studies (>770,000 inseminations) had a weighted advantage of $0.9 \%$ ( $0.7 \%$ unweighted advantage) compared with semen packaged in $0.5-\mathrm{mL}$ straws (Table 1 ). In 2 studies in which palpated conception rates were obtained, the weighted advantage of the $0.25-\mathrm{mL}$ versus the $0.5-\mathrm{mL}$ straw was $0.2 \%$ ( $0.4 \%$ unweighted advantage; Table 1).

Table 2 summarizes paired $t$-test results for 13 studies in which pregnancy outcome was measured by nonreturn rates $(\mathrm{n}=12)$ or serum pregnancy-specific protein B $(\mathrm{n}=1)$. The mean difference $(0.51 \%)$ favor- 
Table 2. Results of a paired $t$-test (mean logit) comparing pregnancy for 0.25 - and 0.5 -mL straw AI

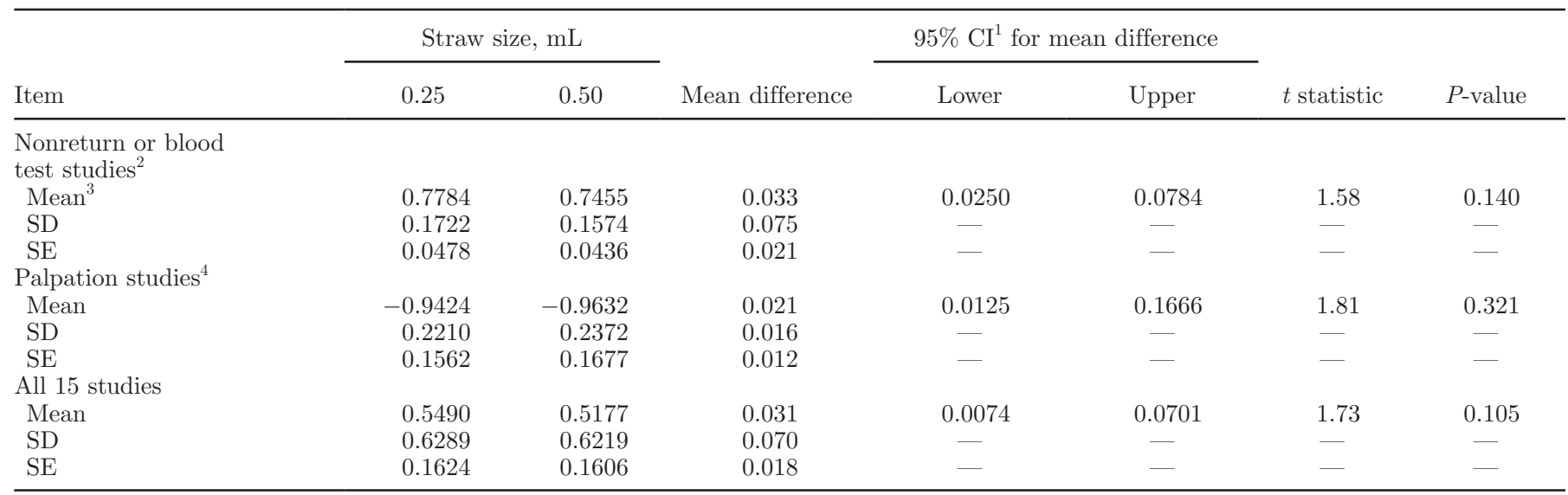

${ }^{1} \mathrm{CI}=$ confidence interval.

${ }^{2}$ Studies having similar percentage outcomes ranging from 62.0 to $76.7 \%$ measured by nonreturn rates $(\mathrm{n}=12)$ or by a blood test (pregnancyspecific protein $\mathrm{B} ; \mathrm{n}=1$ ).

${ }^{3}$ Actual proportion $(p)$ values can be calculated from the mean logit: $p=\left(e^{\text {mean }}\right) /\left(1+e^{\text {mean }}\right)$.

${ }^{4}$ Two studies having similar percentage outcomes ranging from 24.4 to $31.3 \%$ measured by palpated conception rates.

ing the $0.25-\mathrm{mL}$ straw resulting from the unweighted logits of proportion values was not significant $(P=$ $0.14)$. Similar results occurred for the 2 conception-rate studies in which the mean difference did not differ $(P$ $=0.32$ ). When all 15 studies were compared, the mean difference almost tended $(P=0.105)$ to favor the 0.25 mL straw.

Table 3 summarizes the weighted logistic regression analyses. For the 13 studies with the interaction model, straw size $(P=0.079)$ and the interaction $(P=0.075)$ between straw size and study tended to be significant, whereas variation among studies was large $(P<0.001)$. Omitting the interaction resulted in a mean difference $(P<0.001)$ between straw sizes. Compared with that of the $0.5-\mathrm{mL}$ straw, the odds of having a greater nonreturn rate for the $0.25-\mathrm{mL}$ straw were $3.5 \%$. This translates into a nonreturn rate advantage of $0.49 \%$ for the $0.25-\mathrm{mL}$ straw. Analyses of the 2 conception rate studies detected differences $(P<0.001)$ between the 2 studies, but no effect of straw size or the interaction was detected with this small sample size.

When 3 studies were eliminated (Cassou, 1968, 1972; Kaproth et al., 2005) because of confounding factors described previously, the interaction model identified no straw size effect $(P=0.227)$, but significant effect of study $(P<0.001)$ and interaction $(P=0.042)$. In the reduced model with no interaction, differences among studies again were detected $(P<0.001)$, but not between straw sizes $(P=0.325)$. The mean nonreturn rate difference was unchanged at $0.49 \%$.

Results of all 15 studies were similar to those for the 13 studies. Again, compared with the 0.5-mL straw, the odds of having a greater nonreturn or greater concep- tion rate for the $0.25-\mathrm{mL}$ straw were $3.5 \%$ in the model without the interaction term.

The meta-analyses produced similar results regardless of whether a fixed-effect or random-effect model was applied to all 15 studies (Figure 1). Odds ratios of 2 of the 15 studies favored the 0.5 - $\mathrm{mL}$ straw, whereas odds ratios in the remaining 13 studies favored the $0.25-\mathrm{mL}$ straw. Although the odds ratios were $>1$ in these 13 studies, the $95 \%$ confidence limits included 1.0 revealing no significant difference in 9 of 13 studies. The average odds of having a greater pregnancy outcome with the $0.25-\mathrm{mL}$ straw were 3 to $4 \%$ greater $(P<0.05)$. The expected proportion of difference in pregnancy outcome translated into an actual difference of $0.74 \%$.

\section{DISCUSSION}

The 3 statistical methods used to determine differences in pregnancy outcomes of cattle inseminated with semen packaged in either French straw size produced consistent findings. When semen was packaged in the 0.25 -mL straw, the average odds of improving pregnancy outcomes ranged from 3 to $4 \%$, but only represented a small increase in pregnancy outcomes of $<1 \%$ (ranging from 0.49 to $0.74 \%$ ). This small difference persisted even when 3 confounded studies (Cassou, 1968, 1972; Kaproth et al., 2005) were eliminated from the logistic regression analyses.

The greater surface-to-volume ratio of the $0.25-\mathrm{mL}$ straw facilitated faster cooling rates than the $0.5-\mathrm{mL}$ straw, allowing for slight advantages in post-thaw sperm survival in some freezing systems (Senger et 
Table 3. Logistic regression ANOVA (with and without interactions), mean logit, and mean differences between straw sizes (0.25 vs. $0.5 \mathrm{~mL}$ ), odds ratios, and confidence intervals (CI)

\begin{tabular}{|c|c|c|c|c|c|c|c|c|}
\hline \multirow[b]{2}{*}{ Source of variation } & \multirow[b]{2}{*}{$P \leq$} & \multicolumn{2}{|c|}{ Straw size, $\mathrm{mL}$} & \multirow[b]{2}{*}{ Mean difference } & \multirow[b]{2}{*}{ SE } & \multirow[b]{2}{*}{ Odds ratio } & \multicolumn{2}{|c|}{$95 \% \mathrm{CI}$} \\
\hline & & 0.25 & 0.50 & & & & Lower & Upper \\
\hline \multicolumn{9}{|c|}{ Nonreturn or blood test studies ${ }^{1}$} \\
\hline \multicolumn{9}{|l|}{ With interaction } \\
\hline Straw size & 0.0790 & $0.779^{2}$ & 0.746 & 0.0326 & 0.0185 & 1.033 & 0.997 & 1.072 \\
\hline Study & 0.0001 & - & - & - & - & - & - & - \\
\hline Interaction & 0.0746 & - & - & - & - & - & - & - \\
\hline Study & 0.0001 & - & - & - & - & - & - & - \\
\hline \multicolumn{9}{|l|}{ Palpation studies ${ }^{3}$} \\
\hline \multicolumn{9}{|l|}{ With interaction } \\
\hline Straw size & 0.6950 & -0.942 & -0.964 & 0.0220 & 0.0561 & 1.022 & 0.916 & 1.141 \\
\hline Study & 0.0001 & - & - & - & - & - & - & - \\
\hline Interaction & 0.8276 & - & - & - & - & - & - & - \\
\hline \multicolumn{9}{|l|}{ Without interaction } \\
\hline Study & 0.0001 & - & - & - & - & - & - & - \\
\hline Interaction & 0.1351 & - & - & - & - & - & - & - \\
\hline \multicolumn{9}{|l|}{ Without interaction } \\
\hline Straw size & 0.0001 & 0.550 & 0.516 & 0.0347 & 0.0049 & 1.035 & 1.025 & 1.045 \\
\hline Study & 0.0001 & - & - & - & - & - & - & - \\
\hline
\end{tabular}

${ }^{1}$ Studies having similar percentage outcomes ranging from 62.0 to $76.7 \%$ measured by nonreturn rates $(\mathrm{n}=12$ ) or by a blood test (pregnancyspecific protein $\mathrm{B} ; \mathrm{n}=1)$.

${ }^{2}$ Actual proportion $(\mathrm{p})$ values can be calculated from the mean logit: $\mathrm{p}=\left(\mathrm{e}^{\text {mean }}\right) /\left(1+\mathrm{e}^{\text {mean }}\right)$.

${ }^{3}$ Two studies having similar percentage outcomes ranging from 24.4 to $31.3 \%$ measured by palpated conception rates.

al., 1983; Kroetsch, 1992). A cooling rate $\times$ package size interaction for sperm motility and percentage intact acrosomes was detected by Senger et al. (1983), leading the authors to conclude that semen packaged in $0.25-\mathrm{mL}$ French straws should be cooled at slower rates than that in $0.5-\mathrm{mL}$ French straws. In contrast, in large-capacity freezing tanks specifically engineered for static vapor freezing of $0.5-\mathrm{mL}$ straws, the $0.25-\mathrm{mL}$ straw had no advantage in post-thaw sperm survival (Senger et al., 1983; J. Mel DeJarnette, Select Sires, Plain City, $\mathrm{OH}$; personal communication).

The characteristics of the $0.25-\mathrm{mL}$ straw that allowed for the faster freezing rate (large surface-to-volume ratio) make this straw size more sensitive to thermal insult during straw retrieval and after thawing. Extensive comparisons of thermal sensitivity of the 2 straw sizes to the effects of thermal insult during straw retrieval from the liquid nitrogen refrigerator were mimicked by exposing frozen straws to $20^{\circ} \mathrm{C}$ for intervals of $15 \mathrm{~s}, 30$ $\mathrm{s}$, or 1,2 , and 4 min before plunging them back into liquid nitrogen (Berndtson et al., 1976). In that study, the temperature inside $0.25-\mathrm{mL}$ straws rose much more rapidly than that in the $0.5-\mathrm{mL}$ straw that were exposed to $20^{\circ} \mathrm{C}$ from 0 to $4 \mathrm{~min}$. Straws were returned to liquid nitrogen temperatures, mimicking exposures that would occur during the on-farm straw retrieval process. After $30 \mathrm{~s}$ of exposure, little to no loss of motility was reported for sperm packaged in $0.5-\mathrm{mL}$ straws, whereas reduction in post-thaw sperm motility was $80 \%$ for sperm packaged in 0.25 -mL straws. These findings indicated that inseminators must exercise a greater degree of thermal control and protection (both pre- and post-thaw) when working with 0.25 -mL straws.

Although fertility of sperm packaged in $0.25-\mathrm{mL}$ vs. 0.5 -mL straws has been researched for $40 \mathrm{yr}$ (Table 1), most studies were conducted in Europe by highly skilled professional technicians. The recognized variation in AI technician proficiency (Berndtson et al., 1976) as a function of the large percentage of herdsman inseminators was identified as a limitation to successful $\mathrm{AI}$ and may have been a factor in not implementing the $0.25-\mathrm{mL}$ straw in the US market. Kupferschmied (1972) compared the nonreturn rates of $0.25-\mathrm{mL}$ versus $0.5-\mathrm{mL}$ straws used by AI technicians classified as "good" or "poor" based on nonreturn rates before trial initiation. Although nonreturn rates of "good" technicians were similar for the 2 straw packages, nonreturn rates among "poor" technicians were greater for 0.5$\mathrm{mL}$ than for $0.25-\mathrm{mL}$ straws. The authors interpreted these results to indicate that 0.25 -mL straws were more sensitive to improper semen handling by the "poor" technicians. Presently, no large-scale studies are avail- 
Study

MMB (1968)

Cassou (1968)

Malmberg and Dryendahl (1969)

Cassou (1972)

Kupferschmied-"Good" (1972)

Kupferschmied-"Poor" (1972)

Select Sires (1972)

MacPherson et al. (1974)

Kroetsch-1 20M (1992)

Kroetsch-1 30M (1992)

Kroetsch-2 (1992)

Johnson et al. (1995)

Kaproth et al. (2005)

Michael et al. (2003)

Schenk and Everett (2007)

Random effects

Fixed effects

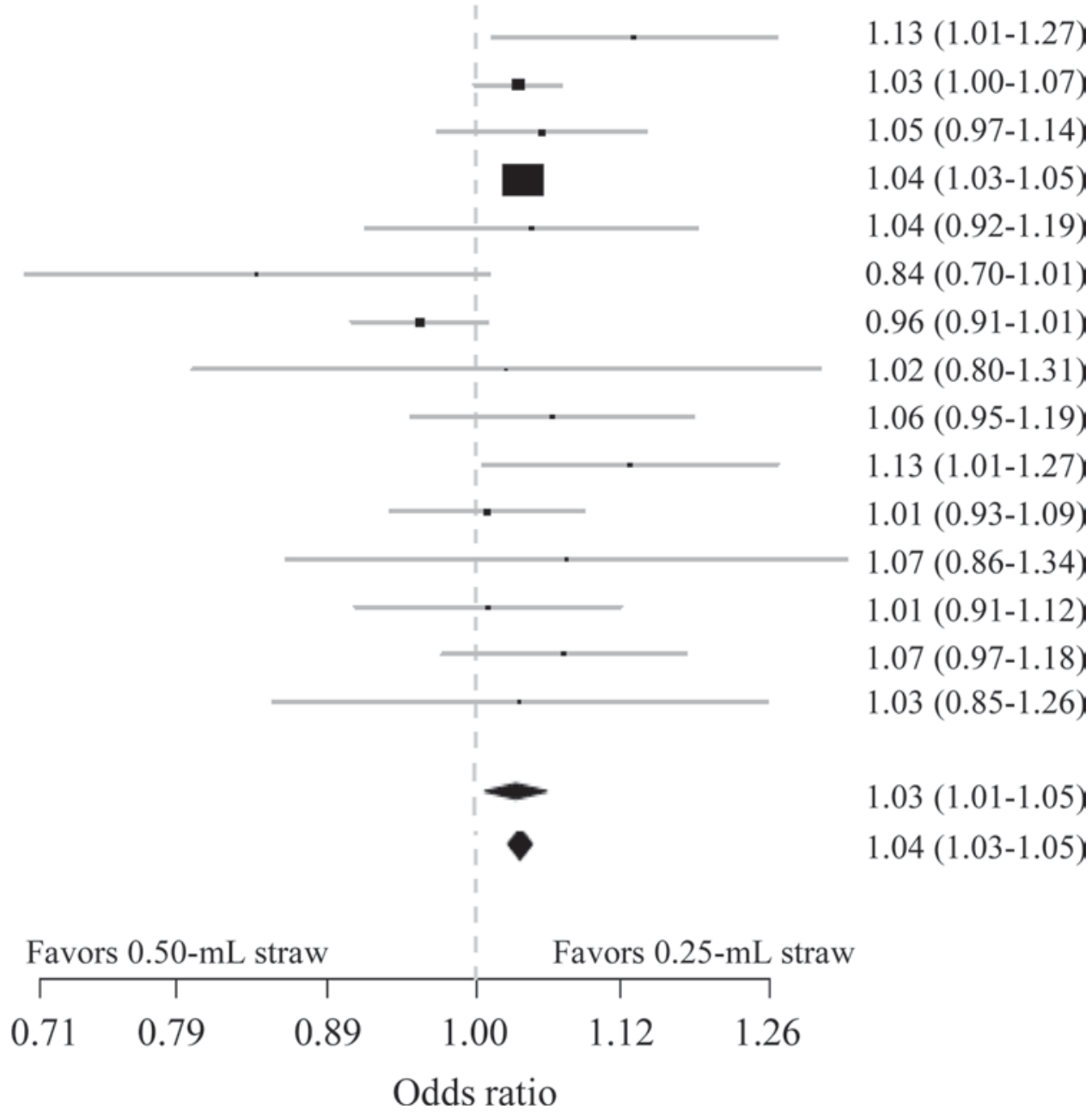

Odds ratios $(95 \% \mathrm{CI})$

$1.13(1.01-1.27)$

$1.03(1.00-1.07)$

$1.04(0.92-1.19)$

$0.84(0.70-1.01)$

$0.96(0.91-1.01)$

$1.02(0.80-1.31)$

$1.06(0.95-1.19)$

$1.13(1.01-1.27)$

1.01 (0.93-1.09)

$1.07(0.86-1.34)$

1.01 (0.91-1.12)

1.07 (0.97-1.18)

$1.03(0.85-1.26)$

$1.03(1.01-1.05)$

1.04 (1.03-1.05)

Fixed effects

\section{Odds ratio}

Figure 1. Forest plot showing odds ratios and their $95 \%$ confidence intervals (CI) for individual studies comparing fertility assessed by nonreturn rates, pregnancy-specific protein $\mathrm{B}$, or palpated conception rates for cattle inseminated with semen packaged in either 0.25 - or 0.5 -mL straws. Box sizes (odds ratios) are proportional to the inverse variance of the estimates. Summary odds ratio estimates of semen package size are shown for each study and overall after applying the DerSimonian-Laird for random effect meta-analysis and the Mantel-Haenszel method for fixed effect meta-analysis. Test of heterogeneity $(P=0.128)$.

able that estimate the effect of variance among lesser skilled herdsman inseminators on conception rates with 0.25 - and $0.5-\mathrm{mL}$ straws.

Gaus (1989) compared the effects of the 0.25- and $0.5-\mathrm{mL}$ French straw and a German modified $0.25-\mathrm{mL}$ straw on post-thaw sperm viability and fertility of bulls classified as good, average, or poor freezeability. The modified $0.25-\mathrm{mL}$ straw was basically the same diameter as the $0.5-\mathrm{mL}$ straw, but half as long (Minitube, Tiefenbach, Germany). Post-thaw sperm motility tended to favor the $0.25-\mathrm{mL}$ French straw compared with the other 2 straw packages, especially among sires of average and poor freezeability. Nonreturn rates of the German modified 0.25 -mL straw were $2.5 \%$ less than those of the $0.25-\mathrm{mL}$ French straw. Nonreturn rates of the 0.25 - and $0.5-\mathrm{mL}$ French straws were not different; however, the means and sample sizes were not published and could not be used as part of this meta-analysis.

Although Kaproth et al. (2005) reported a significant fertility advantage for $0.25-\mathrm{mL}$ straws, it is important to understand how these data were analyzed to appropriately interpret the results. The study was originally designed to compare fertility of the 2 straw packages across 12 sires in 4 large, heifer-raising operations in the United States. In the final statistical analysis, the 0.5-mL straw treatment also contained services from other nonexperimental sires whose semen was processed 
only in $0.5-\mathrm{mL}$ straws. This nonexperimental semen accounted for $55 \%$ of the data analyzed and confounded the comparison of $0.25-$ and $0.5-\mathrm{mL}$ straws. It is impossible to determine whether the $1.5 \%$ difference in nonreturn rate observed in their study resulted from differences in straw package or simply a confounded sire fertility effect as a result of semen of some sires packaged in the $0.5-\mathrm{mL}$ straw, but not packaged in the 0.25 -mL straw.

Most sex-biased semen processed in the United States is supplied in $0.25-\mathrm{mL}$ straws. The $0.25-\mathrm{mL}$ straws were preferred in the early stages of research and development of sexed-biased semen primarily because they provided optimum probability for post-thaw survival of low sperm number dosages as a function of more uniform freezing and thawing rates; thus reducing the dilution effect (Gaus, 1989; Kroetsch, 1992). Little consideration was given to the effect on conception potential or technician competence in commercial application. No difference in conception rates was reported between 0.25 - and $0.5-\mathrm{mL}$ straws in recent field trials with sexed-biased semen in 7 commercial dairies (Schenk and Everett, 2007; Table 1).

Potential economic advantages of reduced costs associated with semen packaged in smaller packages (0.25- vs. 0.5-mL French straws) have been suggested without estimating the magnitude of savings. Coulter and Foote (1974) suggested that with bull numbers and semen inventories constantly increasing, reduced storage requirements of the 0.25 - vs. the $0.5-\mathrm{mL}$ straw was a significant factor. Storage capacity was about half of that of the $0.5-\mathrm{mL}$ straws depending on the type of liquid nitrogen refrigerator storage used (Pickett and Berndtson, 1974). Kroetsch (1992) further concluded that overall improved efficiency with the smaller straw was realized in time, more doses per hour, resources, extender, glycerol, antibiotics, and space (fewer storage tanks, canes, goblets, and can identification tags).

\section{CONCLUSIONS}

Based on the 3 statistical methods used, we conclude that the odds of increasing pregnancy outcomes by packaging semen in 0.25 - $\mathrm{mL}$ versus the US industry standard $0.5-\mathrm{mL}$ straws ranges from 3 to $4 \%$. These odds reflect an actual difference in pregnancy outcome of $<1 \%$ ( 0.49 to $0.74 \%$ ), which in itself does not provide a compelling argument that conversion to the smaller 0.25 -mL straw is in the best interest of the US dairy industry. Depending on the skill and dexterity of the inseminator, the $0.25-\mathrm{mL}$ straw may be more difficult to use, read, and handle, which may (DeJarnette, 2003) or may not result in greater straw loss as a result of breakage during retrieval, storage, or both (Kroetsch, 1992).
Although professional technicians typically may achieve comparable conception rates with the 2 straw types, the potential for technician $\times$ package size interactions on conception rates among herdsman inseminators has been only modestly addressed in $40 \mathrm{yr}$ of research. Although the most compelling argument favoring 0.25 $\mathrm{mL}$ straws is the greater storage and transportation efficiency, which may have only a very minute effect on retail semen price, no economic data are available.

\section{REFERENCES}

Berndtson, W. E., B. W. Pickett, and C. D. Rugg. 1976. Procedures for field handling of bovine semen in plastic straws. Pages 51-60 in Proc. 6th NAAB Tech. Conf. Artif. Insemin. Reprod., Columbia. MO.

Cassou, R. 1968. La miniturisation des paillettes. Proc. 4th Int. Cong. Anim. Reprod. 2:1009.

Cassou, R. 1972. A technique for semen preservation and its application to breed improvement programmes. AI Co-op Centre, 61, L'Aigle, France. Personal publication.

Coulter, G. H., and R. H. Foote. 1974. The economics of selected systems of banking semen vs. maintaining bulls. Pages $67-72$ in Proc. 5th Tech. Natl. Assoc. Anim. Breeders Conf. Artif. Insemin. Reprod., Columbia, MO.

DeJarnette, J. M. 2003. Pros and cons of the half- and quarter-cc straws. Selections. Winter 2003. http://www.selectsires.com/ selections/2003_q1_page10-11.aspx Accessed June 8, 2009.

Gaus, J. 1989. Fortschritte in der Spermaproduktion. RPN Rinderproduktion Niedersachsen GmbH, Verden, Germany.

Johnson, M. S., P. L. Senger, C. H. Allen, D. D. Hancock, B. M Alexander, and R. G. Sasser. 1995. Fertility of bull semen packaged in .25- and .5-milliliter French straws. J. Anim. Sci. 73:19141919.

Kaproth, M. T., H. E. Rycroft, G. R. Gilbert, G. Abdel-Azim, B. F. Putnam, S. A. Schnell, R. W. Everett, and J. E. Parks. 2005. Effect of semen thaw method on conception rate in four large commercial dairy heifer herds. Theriogenology 63:2535-2549.

Kroetsch, T. G. 1992. Experiences with mini-straws. Pages 64-67 in Proc. 14th Natl. Assoc. Anim. Breeders Tech. Conf. Artif. Insemin. Reprod., Columbia, MO.

Kupferschmied, H. 1972. Untersuchungen uber die umstellung von mittleren auf feine pailletten in der rinderbeasamung. Zuchthygiene 7:67-71.

MacPherson, J. W., P. Penner, and G. J. King. 1974. A field trial comparison of bovine semen packed in straws. Can. J. Anim. Sci. 54:47-48.

Malmberg, G., and I. Dryendahl. 1969. En jämförelse av dräktighestsresultatet med fryst sperma I medium-och I fina payetter. Nord. Vet. Med. 21:115-117.

Michael, N., C. Marti, E. Roberts, and M. Pace. 2003. Effect of semen packaged in 0.25 and $0.50 \mathrm{cc}$ straws on conception rate of lactating dairy cows. J. Dairy Sci. 86(Suppl. 1):2. (Abstr.)

Milk Marketing Board (MMB). 1968. The fertility of semen frozen in quarter $\mathrm{cc}$ and half $\mathrm{cc}$ straws. Report of the Breeding and Production Organization, 1967-68. No. 18. Page 114 in Breeding and Production Organization, Milk Marketing Board, Thames Ditton, Surrey, UK.

Pickett, B. W., and W. E. Berndtson. 1974. Preservation of bovine spermatozoa by freezing in straws: A review. J. Dairy Sci. $57: 1287-1301$

Schenk, J. L., and R. W. Everett. 2007. Insemination of Holstein cows with sexed sperm. J. Dairy Sci. 90(Suppl. 1):18. (Abstr.)

Senger, P. L., J. R. Mitchell, and J. O. Almquist. 1983. Influence of cooling rates and extenders upon post-thaw viability of bovine spermatozoa packaged in .25- and .5-mL French straws. J. Anim. Sci. 56:1261-1268.

Wolf, F. M. 1986. Meta-Analysis: Quantitative Methods for Research Sage Publications Inc., Thousand Oaks, CA 